\title{
Community Nursing Placements: student learning experiences during a pandemic and beyond.
}

\author{
Key Words: \\ Community Nursing Placements \\ Student learning in community settings \\ Facilitating student nurse learning in a pandemic \\ Creating student capacity in community nursing \\ Blended learning approaches in community nursing
}

\begin{abstract}
This article explores the current challenges in maintaining community nursing placements as dynamic learning experiences for student nurses during the current pandemic and beyond. Opportunities to create new ways of working and learning are essential to ensure student nurses can continue to be exposed to community nursing care. Developing insight, understanding, knowledge and skills in this unique learning environment is instrumental to encourage the next generation of Community Nurses and increase the future workforce. Suggestions for alternative ways of providing learning experiences during this current period are discussed, which could also be embedded as future strategies in the long term.
\end{abstract}

Navigating the current Covid-19 pandemic in community nursing environments has resulted in, and continues to pose, many difficulties and challenges. Established ways of working have needed to be reviewed to ensure both staff and patients continue to adhere to government public health guidance. Continuing to plan and deliver high quality, effective nursing care for patients remains paramount (Jackson 2020).

Lessons have been learnt from the initial Covid-19 wave in 2020, and while current restrictions are continuing and may well be reinstated in the future, new ways of working are being considered which may well shape the future of community nursing going forward.

\section{Maintaining learning capacity to increase the nursing workforce}

One area which has continued to raise particular challenges in community nursing is maintaining the level of student learning capacity, supervision, and assessment to the extent of pre-pandemic levels. Pre-registration nursing students enjoy a wealth of learning during community placements, develop invaluable knowledge and skills, and gain exposure which may help them consider this dynamic field of practice for their future nursing career (Williamson 2020). Student nurses from both adult and mental health programmes consistently rate a community experience being valuable to understand holistic care and gain insight into the nursing, living, and social care needs of diverse populations. Applications to study Nursing has increased by $32 \%$ with interest in the profession seeing a rise across all age groups. UCAS data suggests 60,000 people have applied to study nursing in the UK for autumn 2021 (Council of Deans 2021). This increase in nursing applications provides a superb opportunity to generate interest in community nursing as a future career, if students are afforded a placement opportunity. Ensuring the continuation of pre-registration nursing programmes is essential for the future nursing workforce and current Health Education England expansion plans reiterate this need. Expanding community nursing placements can help to address future workforce deficits, developing both students 
understanding of this particular aspect of nursing as a future career and also encouraging registered staff's professional development in supervising, assessing and being part of the students learning journey.

As community nursing teams have negotiated approved office space for team meetings and administration requirements in line with government and Public Health guidance, the addition of student nurses in these spaces has been difficult to accommodate. Likewise, government guidance around the use of car sharing has seen individual Trusts/provider organisations and Community Nursing Teams having to make difficult decisions as to whether they consent to a student sharing their car to visit patients. This has resulted in many student nurses forgoing a community experience at this current time due to continuing restrictions.

The community nursing workforce, as with the nursing workforce as a whole, has also seen increased staff sickness in many areas and also required periods of self-isolation in line with their employing organisation and Government guidance. This has resulted in a reduction of Practice Assessors and Practice supervisors in many areas, contributing to a reduction of capacity for student nurse placement experiences. To try to compensate for the possible depletion of the nursing workforce in many areas, and to encourage continuation of student nurse learning experiences, the NMC have reinstated one of the emergency standards implemented earlier in 2020, where a Practice Assessor can also act as a Practice Supervisor for the same student in exceptional circumstances:

Emergency Standard E5.1: Exceptionally, the same person may fulfill the role of Practice Supervisor (PS) and Practice Assessor (PA) during this emergency period. The assessment is to be conducted by a Registered Nurse, Midwife or Nursing Associate with suitable equivalent qualifications for the programme the student is undertaking, and who is not on a temporary register (NMC 2021)

Many lessons have been learned from the first lockdown period in March 2020 with many recent reports suggesting that student nurses continue to have a positive experience in placement. Health Education England (2021) reported of the impact of Covid 19 on students which does suggest that student learning in practice changed significantly during the first wave of Covid, although $90 \%$ of respondents stated that "clinical placements were of a high quality and a good learning environment'. Many students felt they should be in practice helping their registered nurse colleagues, and this was borne out by the numbers of students opting into paid placements, with wanting to feel 'useful' (Townsend 2020). Conversely many students felt a sense of guilt for not opting in, compounded by the constant 'hero effect' portrayed by the media. However, during this recent wave, the NMC have been clear to express that the introduction of paid placements would be for third year students and programmes of study/placement experiences should continue as normal where possible. The aim for all students to complete their programmes of study on time and join the nursing workforce, is of great importance for future care delivery. As stated earlier, the community nursing workforce needs to expand to ensure effective care for an increasing ageing population. Maintaining and increasing student nurse experiences in community setting is seen to be fundamental to assuring this goal (The Kings Fund 2016).

\section{Alternative ways of supporting students in Community Nursing Practice}

Considering alternative ways of working in community settings has afforded the opportunity of developing new and innovative ways of supporting student learning. Challenges are becoming catalysts for change and initial frustrations are now prompting transformation. It is important to share developments and consider if these approaches could work in your team. The following suggestions and examples are not exhaustive but do include aspects of 
learning that community nursing teams may want to consider. One size does not fit all, with transformation success being reliant on the leaders and staff implementing the ideas with a robust underpinning strategy and evaluation mechanism, where preparation is key (Blane 2017).

One particularly challenging aspect of maintaining student placements in community settings relates to car sharing, as mentioned earlier in this article. Government guidance should always be followed, and risks assessed Coronavirus (COVID-19): safer travel guidance for passengers - GOV.UK (www.gov.uk). This guidance should be reiterated to all students and suggests:

- share the transport with the same people each time

- keep to small groups of people at any one time

- open windows for ventilation

- travel side by side or behind other people, rather than facing them, where seating arrangements allow

- face away from each other

- consider seating arrangements to maximise distance between people in the vehicle

- clean your car between journeys using standard cleaning products - make sure you clean door handles and other areas that people may touch

- ask the driver and passengers to wear a face covering

Inform Higher Education Institutes (HEI) of your current approach to this guidance in order that allocations can be considered with individual community nurses who are able to offer a placement opportunity. Explore with the HEI if there are other suitable means of transport, as not all student nurses are car drivers.

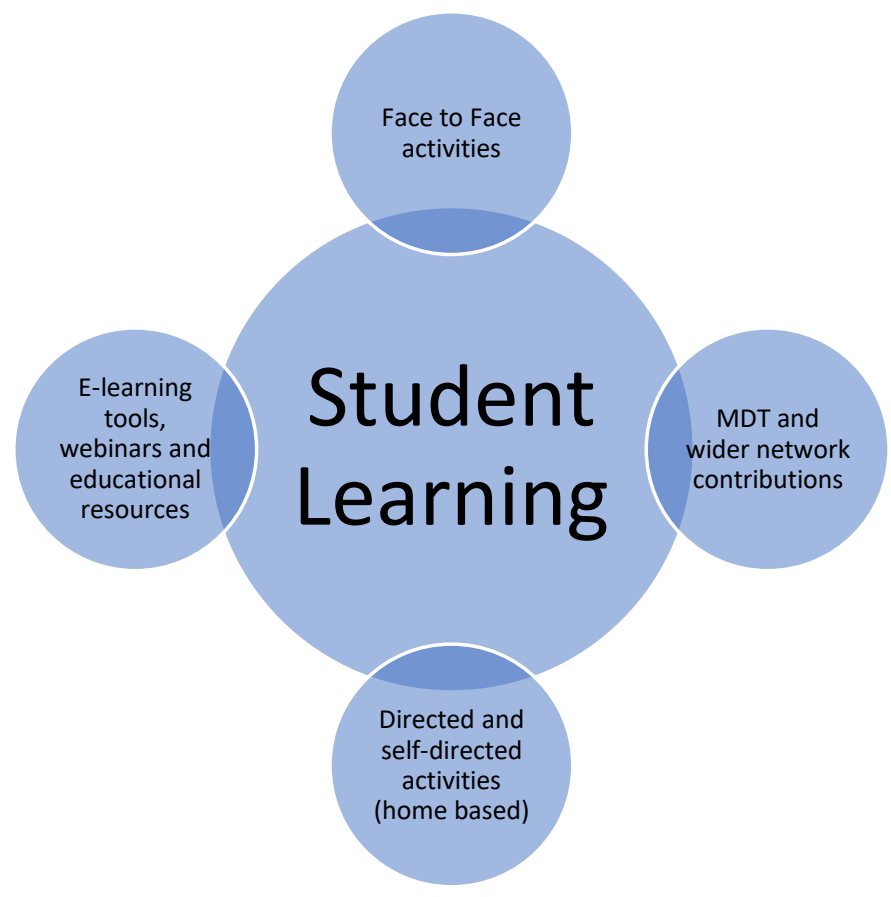

Figure 1: Aspects to consider when planning student learning experiences. 
- Patient acceptability is key to facilitating student learning. It is understandable that many patients may be anxious if more than one person is attending to their nursing needs in the current climate, however also acknowledging patients experiences of household isolation (Brooke and Clark 2020). This requires sensitivity, explanation, and appropriate planning. Patients should not feel pressured into accepting a student nurse into their home, however with appropriate social distancing measures student nurse involvement may be acceptable in some circumstances with patient consent. Student nurses can observe direct care from a distance, or a more experienced student nurse could deliver care with the community nurse observing from a safe social distance. Methods of communication is a key focus area to discuss with students, in particular relating to the impact of wearing of masks/PPE.

- Simulated Practice is one way to promote community nursing knowledge and skills in a safe environment. If used creatively, realistic scenarios can be used to good effect in translating their learning to clinical practice (Gunowa et al 2018). This requires collaborative working between the HEI and Practice Partners to ensure relevant learning outcomes are incorporated and reflection is encouraged. Consider telephone and video consultations where a member of the community nursing team could act as a patient. These types of consultation have increased at a rapid speed during the past year in GP practices and are likely to become a 'normal' method of interaction in many wider health care interactions, including community settings (Thornton 2020).

- Office Space is at a premium. Social distancing requirements could mean students may not be allowed into these spaces. Consider alternative arrangements where staff and students are rostered for office time. This could include hot desking and using corporate spaces/meeting rooms. Students could complete 'mock or simulated' administration tasks from home and discuss with their PS/PA the following day or at the end of the day via phone or virtual technologies. This could include reflecting on a case study/episode of care, where confidentiality and anonymity is maintained. This does take time to prepare to ensure relevant competencies are included but can be used again for future students. Liaising with your organisations Practice Facilitator/Educator and HEI will help to inform this practice and ensure all regulations are met. With any virtual technology used, governance arrangements and data protection must be adhered to in order to protect patient confidentiality and ensure appropriate computer malware protection is assured.

- Multidisciplinary working is a requirement of NMC educational standards for nursing students (NMC 2018) so this is a great way of increasing student experiences. Planning student placements to include these opportunities with a variety of health and social care professionals gives space for all team members. Consider voluntary agencies, charities, and specialist services who may be able to involve student learning in face to face clinics or via online formats. Check your Trust/organisation IT policy for online home working. Can you provide students with laptops with appropriate intranet access for offsite working, which includes remote secure desk top support. Also consider this type of access if students were within a University building/setting.

- Corporate placements are excellent learning experiences for final year students. Ask your Team leaders and operational managers if students can spend a part (or all) of their placement time with corporate teams to understand and develop their leadership skills. This could include attendance (virtual or otherwise) at director meetings, strategic governance discussions, workforce meetings, audit reviews, stakeholder meetings etc. 
- Using the full range of shift patterns can help to increase the number of students accessing a community experience. These can be scheduled to ensure students experience all shift patterns at different times. An example of a student learning journey for one week can be seen in Table 1. Another student could have a plan incorporating these activities at opposite times and including weekends to accommodate both students learning opportunities.

\begin{tabular}{|l|l|l|}
\hline \multicolumn{1}{|c|}{ Date } & \multicolumn{1}{|c|}{ AM } & \multicolumn{1}{c|}{ PM } \\
\hline Monday & $\begin{array}{l}\text { Clinical visits with } \\
\text { community Practice } \\
\text { Assessor/ Practice } \\
\text { Supervisor (PA/PS) }\end{array}$ & $\begin{array}{l}\text { working at home utilising } \\
\text { case scenarios and } \\
\text { reflection. Discussion with } \\
\text { PA/PS at 4pm }\end{array}$ \\
\hline Tuesday & $\begin{array}{l}\text { Clinical visits with } \\
\text { community Practice } \\
\text { Assessor/ Practice } \\
\text { Supervisor (PA/PS) }\end{array}$ & $\begin{array}{l}\text { (virtual) attending webinar } \\
\text { and peer led journal club. } \\
\text { Simulation discussion with } \\
\text { supervisor at 3.30pm }\end{array}$ \\
\hline Wednesday & Working with AHP team & $\begin{array}{l}\text { (virtual) Reflection and } \\
\text { presentation of learning to } \\
\text { supervisor/assessor }\end{array}$ \\
\hline Thursday & $\begin{array}{l}\text { Working at home: Case } \\
\text { study review }\end{array}$ & $\begin{array}{l}\text { Clinical visits with evening } \\
\text { service DN team }\end{array}$ \\
\hline Friday & $\begin{array}{l}\text { Virtual discussion with } \\
\text { PA/PS relating to weeks } \\
\text { learning experiences }\end{array}$ & $\begin{array}{l}\text { Clinical visits with evening } \\
\text { service DN team }\end{array}$ \\
\hline
\end{tabular}

Table 1: An example of a student learning journey incorporating blended learning approaches.

- A Blended Learning approach can be incorporated as a long-term strategy, in addition to being a short-term solution in the current climate. Face to face learning, virtual learning, and directed/self-directed learning can be used effectively together to facilitate a great community nursing experience for students. Preparation is key, with initial planning needed to develop robust scenarios, schedule activities/days with team members, organise rota's, ensure IT systems are available, develop virtual student forums for peer networking, access relevant virtual learning tools to share with students, adopt a coaching approach, schedule regular phone/virtual discussions to monitor progression. In addition to drawing on your local $\mathrm{HEI}$ resources, E learning for Health have some useful learning materials to support students' experiences. There are numerous webinars available where students can gain relevant transferable knowledge and information, which they can subsequently disseminate to the community team as part of a teaching session. Social media journal clubs which can be peer led can also encourage groups of students to engage in critical appraisal skills, reviewing relevant best evidence (Ferguson et al 2016). Final year student nurses can present a teaching session online to other students/staff as part of their episode of care. 
- Practice Facilitators/Practice Educators (PF's/PE's) can be invaluable sources of support to facilitate student learning. Student forums can be scheduled and implemented by PF's/PE's across community team areas to reflect on learning and discuss specific aspects of community care. This could also include case study reviews and student presentations, either virtually or within NHS Trust/ organisation education centres. Identified 'student links' can be considered which involves a named individual having a lead for student support in a neighbourhood team/area. These support links would work with PF/PE's to help enable student learning and identify new ways of working. This also facilitates staff continuing professional development.

- Collaborate with your HEI to ensure students are prepared for the 'types' of experience they are likely to encounter in your community setting. Preparation for clinical practice should start within the HEl setting and continue as part of the student induction within the first days of practice. It is important the information students receive is up to date and reflects the reality of the setting. Students should know what will be expected of them, the opportunities available, and the possible changes to their learning experiences.

\section{Conclusions}

Planning and preparation for student learning is always important, even more so during the current pandemic. Students can bring a wealth of transferable skills and look forward to a community nursing experience with motivation and enthusiasm. Therefore, it is paramount for both community team leaders and all staff to continue to facilitate student placement opportunities as much as they are able. This requires thinking and working differently within government and organisation guidance/policy. The benefits of having students in these settings are numerous, and with a positive experience will contribute to the future community nursing workforce. Sharing of ideas are needed to promote innovative practice across regions. It is recommended you and your teams consider sharing the implementation of strategies through your regional HEE quality leads, Trust/organisation workforce meetings, and with your HEl's to disseminate impact.

\section{Key Points}

- Community Trusts should continue to facilitate student learning experiences during this current pandemic to encourage exposure to community nursing as a possible future career.

- Creative ways of working can be implemented to facilitate student learning in community settings.

- Including the multi-disciplinary team and corporate placement experiences can expand learning opportunities for students.

- A blended learning approach can be embedded in all current and future community nursing placements.

- Preparation and collaboration with all stakeholders/HEl's is key to successful implementation of these initiatives. 


\section{Reflective questions:}

- Consider how you engage with your local HEl in implementing educational innovations in practice. Consider inviting a representative to your next team meeting.

- List all the possible student learning opportunities available across your area, including MDT and wider voluntary/corporate services. Discuss these with your Practice Facilitator/Educator and how you feel these might be incorporated to a placement experience.

- How much do you know about blended learning? Reflect on the advantages and disadvantages of this approach and how you can implement some of the suggestions above.

- Reflect on your current practices during this pandemic, what has changed in your approach to student learning. Share these with your team and develop a team strategy to take forward.

\section{References}

Blane H. (2017) The 7 Principles of Transformational Leadership: Create a mindset of passion, innovation, and growth. US, New Page Books.

Brook J. and Clark M. (2020) Older people's early experience of household isolation and social distancing during COVID-19. Journal of Clinical Nursing, Vol 29, p4387 - 4402.

Council of Deans (2021) UCAS data shows record number of applicants to nursing | Council of Deans of Health (accessed 18.02.21)

NMC (2018) Standards for Education: Standards for nurses - The Nursing and Midwifery Council (nmc.org.uk) Accessed 16.02.21

Ferguson C., DiGiacomo M., Gholizadeh L., Ferguson L., Hickman L. (2016) The integration and evaluation of a social-media facilitated journal club to enhance the student learning experience of evidence-based practice: A case study. Nurse Education Today, Vol 48, p123128.

Gunowa NO, Elliot K, and McBride M. (2018) Nursing Simulation: a community experience. British Journal of Community Nursing Vol 23 (4), p174-178.

Jackson D. (2020) Life in the Pandamic: Some reflections on nursing in the context of COVID-19. Journal of Clinical Nursing, Vol 29, p2041-2043

The Kings Fund (2016) Understanding Quality in District Nursing Services. London, The Kings Fund

Thornton J. (2020) Covid -19: how coronavirus will change the face of general practice forever. BMJ, Vol 368, p1279

Townsend MJ (2020) Learning to nurse during the pandemic: a student's reflections. British Journal of Nursing, Vol 29 (16), p972-973.

Williamson GR., Roweb LM., Knowsleb S., Kaneb A. (2020) Preparation and support for students in community placements: A mixed methods study. Nurse Education in Practice Vol 44, p1-6 